
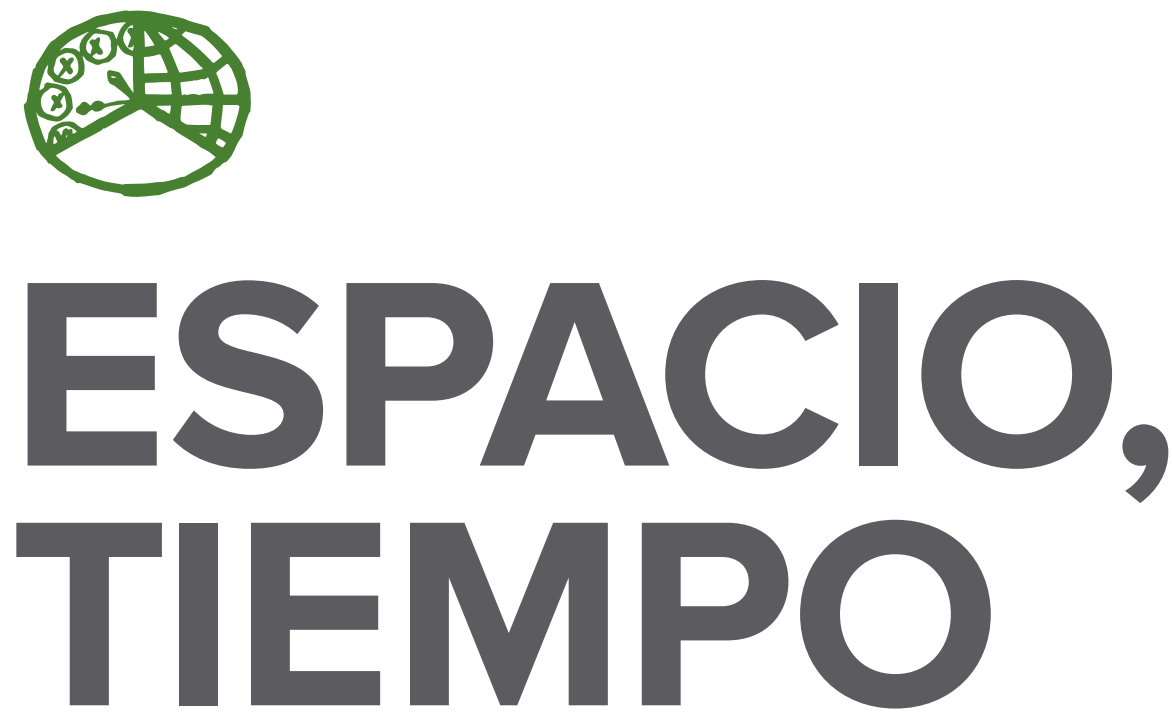

AÑOS 2013-2014

ISSN 1130-2968

E-ISSN 2340-146X
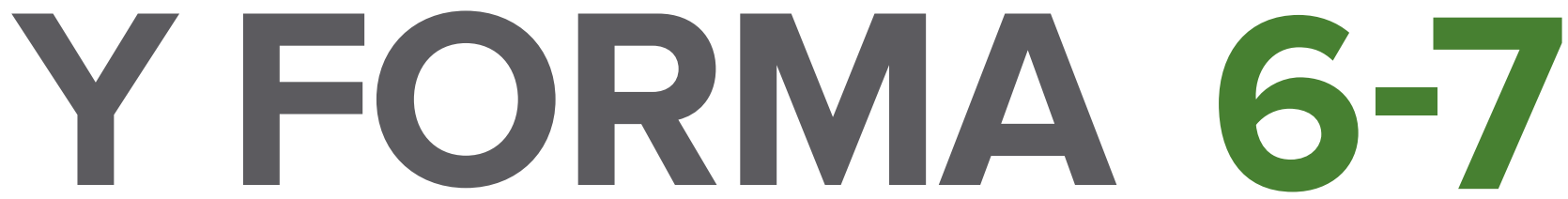

SERIE VI GEOGRAFÍA

REVISTA DE LA FACULTAD DE GEOGRAFÍA E HISTORIA 

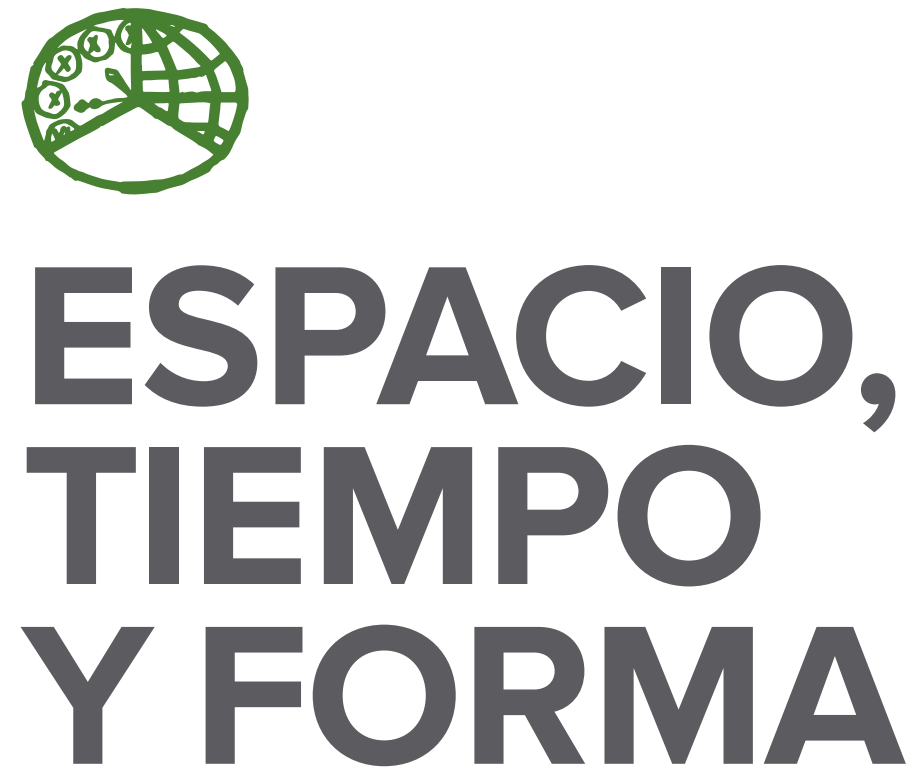

AÑOS 2013-2014

ISSN 1130-2968

E-ISSN 2340-146X

SERIE VI GEOGRAFÍA

REVISTA DE LA FACULTAD DE GEOGRAFÍA E HISTORIA

DOI: http://dx.doi.org/10.5944/etfvi.6-7.0

\section{UกED}

UNIVERSIDAD NACIONAL DE EDUCACIÓN A DISTANCIA 
La revista Espacio, Tiempo y Forma (siglas recomendadas: ETF), de la Facultad de Geografía e Historia de la UNED, que inició su publicación el año 1988, está organizada de la siguiente forma:

$$
\begin{aligned}
& \text { SERIE I - Prehistoria y Arqueología } \\
& \text { SERIE II - Historia Antigua } \\
& \text { SERIE III - Historia Medieval } \\
& \text { SERIE IV - Historia Moderna } \\
& \text { SERIE V - Historia Contemporánea } \\
& \text { SERIE VI - Geografía } \\
& \text { SERIE VII - Historia del Arte }
\end{aligned}
$$

Excepcionalmente, algunos volúmenes del año 1988 atienden a la siguiente numeración:

$$
\begin{aligned}
& \mathrm{N} .^{\circ} 1 \text { - Historia Contemporánea } \\
& \mathrm{N}^{\circ} 2 \text { - Historia del Arte } \\
& \text { N. }{ }^{\circ} 3 \text { - Geografía } \\
& \mathrm{N} .^{\circ} 4 \text { - Historia Moderna }
\end{aligned}
$$

ETF no se solidariza necesariamente con las opiniones expresadas por los autores.

Espacio, Tiempo y Forma, Serie vi está registrada e indexada, entre otros, por los siguientes Repertorios Bibliográficos y Bases de Datos: DICE, ISOC (CINDOC), RESH, IN-RECH, Dialnet, e-sPacio, UNED, CIRC, MIAR, FRANCIS, PIO, ULRICH'S, SUDOC, 2DB, ERIH (ESF).

\author{
UNIVERSIDAD NACIONAL DE EDUCACIÓN A DISTANCIA \\ Madrid, 2013-2014 \\ SERIE VI - GEOGRAFÍA N. ${ }^{\circ} 6-7,2013-2014$ \\ ISSN 1130-2968 · E-ISSN 2340-146x \\ DEPÓSITO LEGAL \\ M-21.037-1988 \\ URL \\ ETF VI · GEOGRAFÍA · http://revistas.uned.es/index.php/ETFVI \\ DISEÑO Y COMPOSICIÓN \\ Sandra Romano Martín · http://sandraromano.es \\ Ángela Gómez Perea · http://angelagomezperea.com \\ Impreso en España · Printed in Spain
}

(c) (i) (8) Esta obra está bajo una licencia Creative Commons

Reconocimiento-NoComercial 4.0 Internacional. 


\title{
ESTRATEGIAS TERRITORIALES PARTICIPATIVAS COMO INSTRUMENTOS DE DIAGNÓSTICO Y PROSPECTIVA, EN EL CONTEXTO EUROPEO DE LOS FONDOS DE COHESIÓN 2014-2020: EL CASO DE VILLENA (ALICANTE)
}

\section{TERRITORIAL PARTICIPATORY STRATEGIES AS INSTRUMENTS OF DIAGNOSIS AND PROSPECTIVE, IN THE EUROPEAN CONTEXT OF THE FUNDS OF COHESION 2014-2020 IN VILLENA (ALICANTE)}

\author{
Antonio Martínez Puche ${ }^{1}$, Salvador Martínez Puche ${ }^{2}$, Joaquín Palací Soler \\ \& Vicente Zapata Hernández ${ }^{4}$ \\ Recepción: 21/11/2014 · Aceptación: 16/01/2015 \\ Dol: http://dx.doi.org/10.5944/etfvi.6-7.0.14852
}

\section{Resumen ${ }^{5}$}

Las Estrategias Territoriales de carácter participado, se han convertido en el instrumento válido para diagnosticar las necesidades de un territorio. La Unión Europea obliga la aplicación de esta herramienta en el nuevo contexto del periodo 20I4-2020. En el municipio de Villena (Alicante), se realizó una estrategia territorial integrada, desde hace dos años que ha derivado en un foro económico social, a través del proceso de abajo-arriba. El estudio de caso avala que la ciudadanía sí que es importante y ha participado activamente en una planificación estratégica ya que los nuevos tiempos, en el contexto del desarrollo local, así lo determinan. Se establecen las fases de aplicación, la metodología utilizada y también los resultados obtenidos.

\footnotetext{
1. Director Observatorio de Investigación de Desarrollo Local y Geografía Económica (Geobindel), del Departamento de Geografía Humana. Universidad de Alicante.antonio.martinez@ua.es

2. Departamento Información y Documentación. Área de Publicidad y Comunicación Audiovisual. Universidad de Murcia.s.martinezpuche@um.es

3. Empresa CREA 360, Consultoría de Desarrollo Local y miembro de GEOBINDEL, Alicante. crea360@crea360.es

4. Departamento de Geografía. Facultad de Geografía e Historia Universidad de La Laguna. vzapata@ull.es

5. Proyecto GV/2014/085: «Análisis de la innovación territorial, gobernanza y procesos de resiliencia en la Comunidad Valenciana para el favorecimiento de emprendimientos locales. Identificación de instrumentos, evaluación de indicadores y sistematización de buenas prácticas», Conselleria de Educación Cultura y Deporte, Dirección General de Universidades, Estudios Superiores y ciencia.
} 
Palabras clave

participación ciudadana; estrategia territorial; Fondos de Cohesión; buena práctica en desarrollo local

\section{Abstract}

The participated Territorial Strategies, they have transformed into the valid instrument to diagnose the necessities of a territory. European Union forces the application of this tool in the new context of the period 2014-2020. In the municipality of Villena (Alicante), she was carried out a territorial integrated strategy, for two years that it has derived in an economic Social Forum, through the process bottom-up. The citizenship is important and it has participated actively since in a strategic planning the new times, in the context of the local development, they determine this way it. The application phases settle down, the used methodology and also the obtained results.

\section{Keywords}

civic participation; territorial strategy; Fund of Cohesion; good practice in local development 


\section{INTRODUCCIÓN}

Los gobiernos locales se enfrentan a un desafío importante: los cambios acontecidos en los procesos productivos, políticos, normativos, fiscales y comunicacionales requieren de decisiones y respuestas cada vez más rápidas y flexibles, que maximicen los beneficios de la comunidad, lo cual a su vez también demanda mayores espacios de participación y decisión. Se trata de superar un estilo de administración para adoptar uno de gestión y fomento de aspectos como el liderazgo y el tejido asociativo, en un contexto proactivo y de servicio público del gobierno local ${ }^{6}$, quizás ahora amenazado con las reformas incorporadas por la Ley 27/20I3 de racionalización y sostenibilidad de la Administración Local, del pasado mes de diciembre.

Ante ello, por una parte, tanto los gobiernos nacionales como los organismos internacionales promueven herramientas de gestión, espacios de reflexión y recursos para que los gobiernos locales se incorporen a este nuevo escenario con el desarrollo local participado como catalizador de las nuevas ayudas europeas. Por otra parte, algunos municipios atienden, y han atendido en el pasado, al desarrollo local sólo como un instrumento más para acceder a fondos económicos exógenos para los ayuntamientos, que procedentes de otras administraciones supralocales, ayude a la financiación de proyectos municipales y favorezcan el grado de empleabilidad.

\section{GOBERNANZA O NUEVAS FORMAS DE GOBIERNO. EL PAPEL DE LAS ADMINISTRACIONES LOCALES}

A pesar de las similitudes de problemas existentes y las soluciones, parciales o integrales, adoptadas, en los estudios de casos se observa que la política de desarrollo local toma formas propias en cada uno de los distintos países de la Unión Europea. La forma de organización del estado, el mayor o menor grado de descentralización, el desarrollo e identificación de sistemas productivos locales de empresas, la aplicación de políticas sectoriales o integradas, determinan que las acciones de desarrollo local tengan que ser diferenciadas y analizadas en su contexto territorial

6. El Estatuto del Gobierno Local, la negociación del nuevo modelo de financiación y la ejecución de los proyectos financiados con el Fondo Estatal de Inversión Local, han convertido a los Ayuntamientos en protagonistas destacados durante estos últimos años. Los Gobiernos Locales han afrontado esta década «con la responsabilidad de ayudar al país a salir de la crisis, desde su ámbito de actuación, pero también esperando respuestas a sus demandas históricas de mayor presencia institucional y de mayor capacidad para afrontar los retos sociales y económicos que los ciudadanos les reclaman como Administración más cercana a la gente de la calle. Esas tres cuestiones, aunque de primera magnitud, no son las únicas que han centrado la atención de los Alcaldes y Alcaldesas ni de los Presidentes y Presidentas de Diputaciones, Cabildos y Consejos Insulares, representados en la FEMP. La modernización constante de la Administración Local, con la incorporación de las nuevas tecnologías en todos los municipios, hasta el más pequeño, es otro de esos frentes. Pero también que los Ayuntamientos se conviertan en dinamizadores de la economía, en motores de desarrollo y de generación de empleo, y ayuden al resto de la sociedad y de los agentes sociales y económicos a recuperar el pulso de la economía. Al mismo tiempo, los Gobiernos Locales tienen como objetivo prioritario seguir contribuyendo al bienestar social de sus vecinos, con una calidad cada vez mayor en los servicios que presta desde la «primera línea», como la Administración más cercana y con mayor experiencia en la atención de las necesidades de los ciudadanos. En definitiva, trabajar en políticas relacionadas con la convivencia, la participación, la cultura, la educación, la integración o la ayuda a los más necesitados». Carta Local.es, Federación Española de Municipios y Provincias (FEMP), 9 de enero de 2009. 
(Romero, J. \& Farinos, J., 2OII). De hecho en la actualidad, y frente a las políticas regionales de hace más de tres décadas, un renovado concepto se está imponiendo en la aplicación de las políticas de desarrollo que ha ido evolucionando en la presente década. La gobernanza como metodología y sistema, tiene la capacidad de movilizar capitales, actividades y conocimientos, a través del compromiso y el sentimiento de pertenencia al territorio. Ello permite instituir políticas pero no sustituirlas, ya que posibilita la intervención de un conjunto de instituciones y de actores que no pertenecen a la esfera gubernamental (Delfour, C., 2007: 4I). Así, la gobernanza debería implicar el fomento de la participación en red, del compromiso de las fuerzas vivas, del fomento de los procesos continuados frente a los proyectos finitos, favoreciendo la capacidad de autoevaluación para seguir mejorando. Todo ello teniendo en cuenta la consideración de escalas administrativas y territoriales, así como la capacidad de autonomía en la toma de decisiones por parte de la comunidad local, favoreciendo la participación pública y ciudadana, potenciando la transversalidad y la coordinación en las acciones.

Aquí se destacan algunas grandes tendencias de fondo que sin duda ayudan a entender los nuevos estilos y agendas de gobierno de los territorios en esta nueva era de la información: los procesos de reestructuración del tradicional Estado-nación, los procesos de recomposición social y «homogeneización» territorial, la emergencia de una nueva forma de entender el desarrollo y las aspiraciones de los ciudadanos de tener mayor participación en los procesos de toma de decisiones (Romero GonzÁlez, J., 2005: 60). Mejor Estado y más próximo, nuevos procesos territoriales, desarrollo sostenible y más democracia, constituyen hoy algunos de los elementos más importantes del cambio que exigen nuevas formas de gobierno. En efecto, la evolución de la teoría de la gobernanza, influida por los procesos de europeización y globalización, alude a redes de gobierno, por una parte, y a formas de coordinación entre actores, por otra, que posibilita una nueva forma de entender los límites y oportunidades del Estado en sus relaciones con la sociedad, con formas de gobernar mucho más cooperativos. De hecho, la gobernanza surge en el contexto de la llamada «crisis de la gobernabilidad», discurso éste que enfatiza las relaciones entre los gobiernos y los entes locales, y sus ciudadanos, favoreciendo además la coordinación horizontal entre múltiples agentes sociales en el policy-making o making democracy work (política y democracia participada) (NATERa Peral, A., 2005: 55; FonT, J., Montero, J.R. \& TorCal, M., 2006: 27).

Sin duda, los ayuntamientos como órganos de representatividad de los ciudadanos, más próximo a ellos, y gestores de las políticas locales, se erigen en el instrumento administrativo que más hace en relación a la aplicación de acciones y el estímulo de decisiones en materia del «buen gobierno». La democracia local en Europa ha ido evolucionando y desde hace tres décadas se pueden establecer diferentes formas de articulación, modelos de actuación y niveles de descentralización. Hace cuatro décadas los problemas más acuciantes para los entes locales, era la captación y optimización de recursos básicos y servicios perentorios como el abastecimiento de agua, el asfaltado de calles, la reurbanización de zonas y espacios industriales y comerciales, alcantarillado, etc. Desde hace una década, los ciudadanos, ante nuevas necesidades y renovados contextos, reclaman otro tipo 
de medidas y renovadas soluciones. Las políticas de sostenibilidad, la calidad de vida, la integración y regulación de inmigrantes, el fomento y la aplicación de las nuevas tecnologías, la violencia de género, el fomento del empleo, las prestaciones sociales y sanitarias, entre otras, se han convertido en verdaderos retos para las corporaciones locales de toda Europa, y particularmente en España. La «calidad de la democracia» de los gobiernos locales se basa ya en criterios de eficacia y eficiencia, y los políticos tienen que ir de la mano de los ciudadanos, pero también del tejido productivo, de entes privados y de los técnicos que se encargan del fomento de actividades y prestaciones relacionadas con el desarrollo local y territorial. Y esto es importante, ya que cada vez más los técnicos de desarrollo local, han ido diversificando sus perfiles socioprofesionales, funciones y actuaciones, en relación al contexto territorial en el que ejercen su labor y ejercicio profesional (SANCHís PALACiOS, J.R., 2006). También porque el desarrollo local, ha ido variando en contextos, formas y normativas, lo que hace más importante en la aplicación y desarrollo de proyectos, la buena actitud y disposición de los técnicos y políticos, que incluso la ejecución del gasto de la ayuda y la cualificación profesional (MARTínez PUCHE, A. \& Calvo Palomares, R., 20ii).

Sin duda, la Ley 27/20I3 de diciembre, de Racionalización y Sostenibilidad de la Administración Local, ha supuesto una notable incertidumbre en cuanto a la gestión y rol que deben ocupar las entidades locales. Su incidencia directa en las competencias de muchos ayuntamientos, menores a los 20.000 habitantes (que suponen más del $94 \%$ del total en nuestro país), la asunción de competencias por parte de las Diputaciones Provinciales y la imposibilidad de éstas en cuanto a medios financieros y humanos, están obligando a muchos ayuntamientos a replantearse renovadas funciones, descartando otras, de forma paulatina y atendiendo a sus capacidades financieras y legislativas.

\section{NUEVAS POSIBILIDADES ANTE LA POLÍTICA DE COHESIÓN EUROPEA (2014-2020). LA METODOLOGÍA «INVESTIGACIÓN- ACCIÓN» AL SERVICIO DE LOS GOBIERNOS LOCALES}

La política europea actual en materia de desarrollo local integrado, sienta sus bases en la reforma de los Fondos Estructurales regulada por el Reglamento CEE/2052/88 del Consejo de 24 de junio de I988, desarrollado mediante cuatro reglamentos promulgados el 29 de diciembre de I988 y con entrada en vigor el I de enero de I989. La reforma de los Fondos Estructurales, integró al Desarrollo Local en el cuadro de políticas regionales a través de las Iniciativas Comunitarias (Martínez Puche, A. Pérez, D. \& Sancho Carbonell, l., 200o).

En efecto, el concepto de desarrollo local integrado, se incorpora a las prioridades del Fondo Social Europeo (FSE) y se incluye en la financiación de los programas operativos regionales y de las Iniciativas Comunitarias (I99I-2006) (Horizon, Now, Integra, Adapt, Leader, Urban, Equal, etc.). Con la publicación del Libro Blanco sobre Crecimiento, Competitividad y Empleo, en I993, alcanza un papel prominente vinculado a la explotación de los denominados «nuevos yacimientos de empleo». 
Las cumbres de Ámsterdam y Luxemburgo dieron un nuevo impulso al desarrollo local al incluirlo como una prioridad en la Estrategia Europea por el Empleo que se incorporó como un nuevo título en el Tratado de la Unión.

La Comunidad Europea concebía ya a principios de los ochenta, las políticas de desarrollo local como una estrategia de origen local, orientada a resolver los problemas de las comunidades locales, que se instrumentaba a través de iniciativas que perseguían la creación y el desarrollo de empresas que permitían la creación de empleo. Sin lugar a dudas, en este sentido, una de las aportaciones destacadas fue el programa LEDA (Local Economic Development Action) que trató de crear y divulgar una nueva aproximación al desarrollo territorial (SANCHís PALACiO, J.R., 2006: 23). El programa LEDA se inició en España en I986 por iniciativa de la Dirección General de Empleo, Relaciones Industriales y Asuntos Sociales, que buscaba realizar acciones en treinta y tres zonas piloto con un alto nivel de paro, que abarcaban zonas industriales en declive, regiones rurales, grandes áreas urbanas y regiones mixtas rurales/urbanas (VÁzQUEZ BARQUERo, A., I993: 215).

Este proceso estuvo muy difundido por Europa, ya que las iniciativas respondieron a procesos de reestructuración productiva asociada a sectores económicos muy diferentes y en ciudades y territorios con características diferenciadas. En la investigación de Stöhr (I99I), referida en la publicación de Vázquez Barquero (I993), se destacaron cuarenta y cuatro experiencias, localizadas en áreas rurales, áreas de antigua industrialización, ciudades medias y áreas metropolitanas. Según Valcárcel-Resalt (I996), en España existían 258 experiencias en desarrollo local, donde el ámbito territorial y las características sociodemográficas diferían enormemente. Las políticas de desarrollo local tomaban formas propias en cada uno de los países de la Unión Europea. La forma de organización del Estado, las líneas programáticas de las políticas espaciales de los gobiernos centrales y locales, y la propia historia política y socioeconómica de los países, son algunos de los factores que explicarían las formas diversas de aplicación de las políticas de Desarrollo Local.

La propuesta de reglamento (artículos 28-3I) para el Desarrollo Local de las Comunidades Locales futuro (DLCL), está basada en el enfoque LEADER y concierne a todos los fondos cubiertos por el Marco Estratégico Común (Fondo Europeo de Desarrollo Regional, Fondo Social Europeo, Fondo Europeo Agrícola de Desarrollo Rural, Fondo Europeo de la Pesca y Marítimo y Fondo de Cohesión) en el período de programación 20I4-2020 (los fondos del MEC). El DLCL es una herramienta específica para el uso en el nivel subregional, que es complementaria a otros apoyos al desarrollo en el nivel local. El DLCL puede movilizarse e implicar a las comunidades y organizaciones locales para que contribuyan a alcanzar los objetivos de la Estrategia Europa 2020 de desarrollo inteligente, sostenible e integrador, fomentar la cohesión territorial y lograr los objetivos específicos de la política comunitaria en sus distintos estados miembros a través del desarrollo local participativo y las Inversiones Territoriales Integradas (ITIS). En este sentido la UE ha aprobado cuatro itis para España, la cantábrica, la del Mar Menor de Murcia, la de Cádiz y otra para Extremadura, quedando abierta la posibilidad de desarrollar alguna más, en el área de Teruel vinculada al Instituto de Investigación y Desarrollo Rural-Serranía Celtibérica (FIG. I). 
En general, los objetivos que se persiguen son:

* Animar a las comunidades locales a desarrollar enfoques ascendentes integrados en los casos donde exista la necesidad de responder a los retos territoriales y locales que requieran un cambio estructural;

* Generar capacidad en la comunidad y estimular la innovación (incluida la innovación social), la iniciativa empresarial y la capacidad de cambio mediante el fomento del desarrollo y la detección de potencial sin explorar en comunidades y territorios;

* Promover la propiedad de la comunidad aumentando la participación en las comunidades y generar un sentimiento de implicación y propiedad que aumente la eficacia de las políticas de la UE.

* Asistir a la gobernanza en varios niveles proporcionando una ruta para que las comunidades locales participen plenamente en el desarrollo de la aplicación de los objetivos de la uE en todas las áreas.

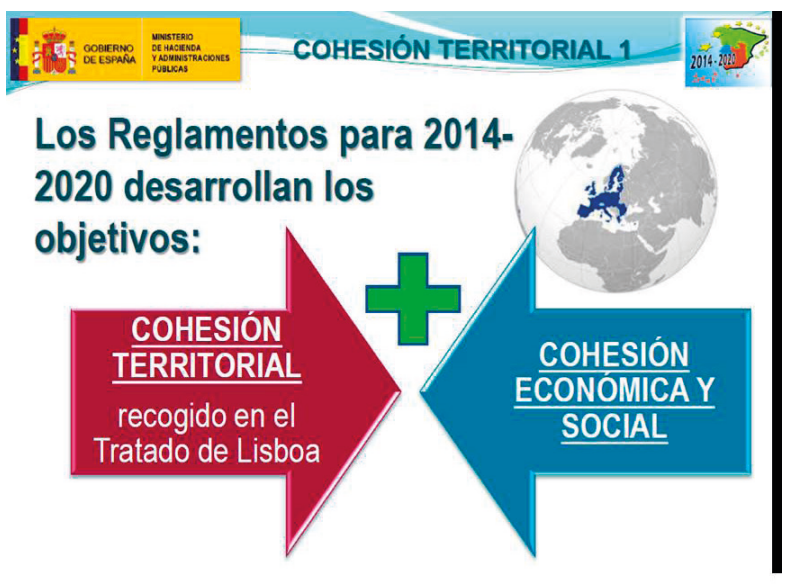

- Cohesión territorial

- Desarrollo Urbano Sostenible Integrado

\section{Desarrollo Local Participativo}

\section{-ITIS}

FIGURA 1. ESQUEMA DE LOS OBJETIVOS GENERALES DE LOS FONDOS DE COHESIÓN (2014-2020) Fuente: Ministerio de Hacienda y Administraciones Públicas.

La Federación Española de Municipios y Provincias (FEMP) ha estado colaborando con la Dirección General de Fondos Comunitarios, del Ministerio de Hacienda y Administraciones Públicas, y con la Comisión Europea en la definición del tramo local del Fondo Europeo de Desarrollo Regional (FEDER) en el período de programación 2014-2020. Dicho tramo local está dividido en dos partes: 500 millones de euros destinados a proyectos concretos de Economía Baja en Carbono, y aproximadamente I.00o millones de euros dirigidos a proyectos integrados de desarrollo urbano sostenible. Entre los requisitos establecidos por parte de la Unión Europea para que los Gobiernos Locales puedan acceder a los fondos destinados a los proyectos integrados, se incluye la elaboración de una Estrategia Integrada para el municipio. Estas Estrategias Integradas se conciben como un instrumento de planificación del desarrollo del municipio en su conjunto, considerando aspectos sociales, económicos, ambientales, con un horizonte temporal determinado, como mínimo el año 2020.

En este sentido desde el Observatorio de Investigación de Geografía Económica y Desarrollo Local (GEOBINDEL), del departamento de Geografía Humana de la Universidad de Alicante, y desde el Máster Oficial de Desarrollo Local e Innovación Territorial (DELEITE-UA), de la misma Universidad, se ha puesto al servicio de los ayuntamientos la elaboración de estrategias participadas y participativas. En 
este contexto, el equipo de trabajo plantea una reflexión, que con tantas iniciativas públicas, inversiones, planes estratégicos, se tiene la evidencia de que no han generado tejido, y tan sólo han dado lugar a infraestructuras y equipamientos, y a documentos de trabajo que acumulan polvo, en cajones, armarios y en el olvido, sin redundar en beneficio de la ciudadanía. Por ello se plantea una necesidad, dotar de significado y contenido palabras, términos y conceptos como participación, ciudadanía, planificación estratégica, inteligencia colectiva, gobierno abierto, gobernanza, representatividad, desarrollo socioeconómico, innovación. «De nada sirve tu intención, sino le pones acción». Las Estrategias Territoriales de los municipios, tienen que ser un instrumento flexible e inductivo, y por tanto sometido a la dinámica social, económica, ambiental, cultural de la localidad que permita una acción de gobierno programática y sistemática (planificada) a partir de un proceso previo de reflexión y análisis participado. Todo ello para establecer un protocolo de actuación de objetivos y acciones, posibilitando a toda la ciudadanía someterlo a una evaluación y seguimiento para definir las líneas básicas que pueden guiar la gestión socioeconómica en el municipio bajo un enfoque integrado y que posibilite generar las condiciones de acogerse a las ayudas europeas de la Política de Cohesión Europea (20I4-2020). Lo que se quiere desarrollar es la metodología «investigación-acción», dónde se generen espacios de encuentro y diálogo entre investigadores, ciudadanía y responsables políticos, que a su vez obtengan retorno, en forma de diagnóstico y propuestas de acciones (FIG. 2).

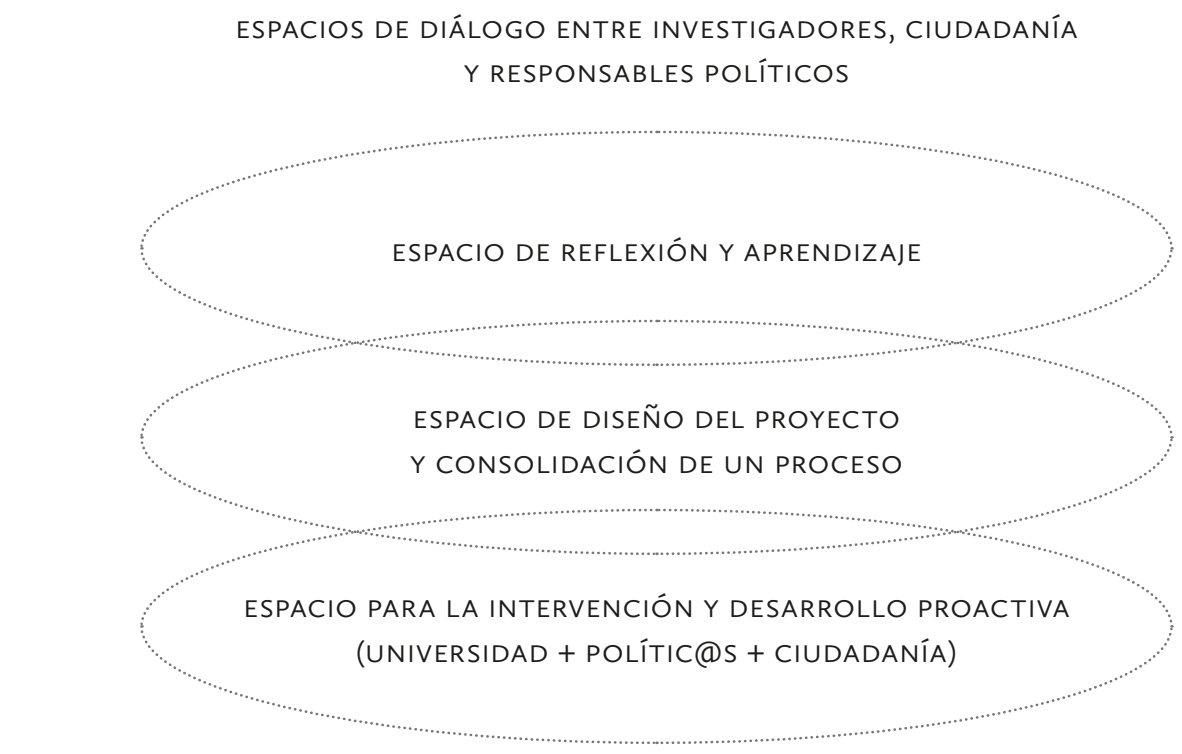

FIGURA 2. ESQUEMA DE LA METODOLOGÍA «INVESTIGACIÓN-ACCIÓN»EN LAS ESTRATEGIAS TERRITORIALES PARTICIPATIVAS MUNICIPALES

Fuente: elaboración propia.

Todo ello al objeto de facilitar la integración del mayor número posible de actores y entidades se posibilita un mayor sentimiento de pertenencia local y el discurso tiene una mayor capacidad para crear un proyecto colectivo que, además de 
cohesionar a la comunidad en torno a unos objetivos propios, sea capaz de proyectarla con la finalidad de buscar las culturas, mercados y capitales necesarios para su desarrollo presente y futuro.

En este sentido la participación pública se entiende como el procedimiento que permite a una sociedad incidir y formar parte en la toma de decisiones sobre políticas que le conciernen (medio ambiente, servicios, cultura, sanidad, inmigración, etc.). En caso contrario, la participación se convierte en la «práctica del mucho decir y del poco decidir y hacer». Por ello, y de manera genérica la Estrategia Territorial de estos municipios, se debería basar en:

I. Identificar las oportunidades en las escalas provincial, comarcal y municipal para el desarrollo de proyectos innovadores en el ámbito del empleo y el desarrollo local

2. Reconocer medios, entornos o territorios innovadores o favorables a la generación y difusión de la innovación

3. Identificar buenas prácticas por sectores y de forma integrada

4. Difundir y fortalecer el concepto de innovación territorial

5. Definir, aplicar y desarrollar una metodología de trabajo para la identificación de oportunidades de innovación, talentos y líderes en el marco local, todo ello a través de la participación ciudadana

6. Informar y sensibilizar sobre la necesidad e importancia de una participación proactiva.

Entre los grupos sociodemográficos con los que trabajar, se deberían proponer a los jóvenes, jubilados, amas de casa, tejido asociativo, sectores socioeconómicos y técnicos municipales, entre otros. Debe primar la voluntariedad y el análisis de aspectos específicos, atendiendo a la naturaleza y características del municipio, como el centro histórico, los polígonos industriales, los espacios naturales y el turismo, etc. Pudiendo llegar, después del análisis, a plantear acciones de tipo instrumental, vinculadas a la ordenación del territorio (como los planes de ordenación urbana y las de preservación y gestión de los recursos naturales) y las de tipo socioeconómico, como las del fomento de nuevos yacimientos de empleo, apoyo al emprendedor y reactivación del empleo, programas todos ellos que se ajustan en la Política de Cohesión Europea (2014-2020).

Las estrategias locales de desarrollo deben ser coherentes con los programas pertinentes de los fondos del Marco Estratégico Común (MEC), a través de los que reciben apoyo. Deben definir el área y población cubiertas por la estrategia; incluir un análisis de las necesidades de desarrollo y el potencial del área, que comprenda un análisis de puntos fuertes, puntos débiles, oportunidades y amenazas; y describir los objetivos, así como el carácter integrado e innovador de la estrategia, incluidas las metas en cuanto a resultados. Las estrategias también deben incluir un plan de acción que demuestre el modo en que los objetivos se plasmarán en proyectos concretos, acuerdos de gestión y supervisión y un plan financiero. 


\section{LA ESTRATEGIA TERRITORIAL DE VILLENA+INNOVACIÓN $(E T V+I)$. UN MODELO EN LOS MUNICIPIOS DE LA COMUNIDAD VALENCIANA}

En abril de 2012 comenzó la ETV+i, un proyecto financiado por el Ayuntamiento de Villena (Alicante) que coordinó el Departamento de Geografía Humana de la Universidad de Alicante. Pronto nos dimos cuenta de que no tenía que ser un diagnóstico al uso ni un estudio descriptivo más, como ha ocurrido en otros casos. La inflación de planes estratégicos desarrollados en la provincia de Alicante obligó a finales de 20I2, a celebrar una reunión para optimizar las iniciativas impulsadas a instancias de distintos organismos: Universidad de Alicante, Cámara de Comercio, Coepa y Diputación provincial, entre otros. El exceso de documentos estratégicos había provocado una notable parálisis en las acciones propuestas ${ }^{7}$. Tampoco había ayudado la aparente desconexión con las realidades del territorio, la ausencia de protagonismo de la ciudadanía, los elevados costes de algunos proyectos presentados y el interés partidista de ayuntamientos y demás instituciones. En este escenario aparecieron sendos planes estratégicos en los municipios de Elche (20II) y Alicante (20I2) que no han contribuido a considerar la planificación estratégica como un instrumento eficaz y eficiente, útil y no solo utilitarista. De hecho, la percepción general es que muchos de estos documentos han servido para realizar un diagnóstico descriptivo, sin proposiciones coherentes ni acciones proactivas ni una verdadera participación pública y ciudadana ${ }^{8}$.

La ETV+i incluyó, entre sus objetivos, conciliar algunas de las directrices de la Estrategia Territorial de la Comunidad Valenciana, aprobada el I3 de enero de 20 II por la Generalitat Valenciana, y sus previsiones para las comarcas del Vinalopó, con los planteamientos derivados del ámbito local villenense. También contempló fomentar, a partir de las proposiciones, un territorio más competitivo en lo económico, más respetuoso en lo ambiental y más cohesionado e integrador en lo social, generando por tanto un valor añadido. No hay que olvidar que Villena es el segundo término municipal más grande de la provincia de Alicante $\left(345 \mathrm{~km}^{2}\right)$, y que junto a un sistema productivo basado tradicionalmente en la fabricación de calzado, también la agricultura y, sobre todo, los servicios juegan un papel de notable relevancia en la economía local.

A lo largo de 2012 y 2013, se realizaron análisis, diagnósticos, talleres, jornadas, coloquios y asambleas ciudadanas con los siguientes objetivos:

* Detectar, identificar y diagnosticar las necesidades reales y potenciales del municipio, agrupándolas por áreas de gestión: economía y empleo, turismo

7. «Los expertos apuestan por revisar los planes estratégicos para reactivar la provincia. El urbanista Alfonso Vegara y los catedráticos Andrés Pedreño y Joaquín Melgarejo abogan por impulsar proyectos e ideas que no requieran grandes inversiones», Diario Información, sábado 10 de noviembre de 2012.

8. Impulsa Alicante. Diagnóstico competitivo y grado de desarrollo de la ciudad de Alicante (2012), Deloitte y Ayuntamiento de Alicante; Elche. Proyecto Ciudad (2011), Fundación Metrópoli y Ajuntament d' Elx. 
y patrimonio, medio ambiente y agricultura, urbanismo e infraestructuras, gobernanza y ciudadanía, etc.

* Sistematizar la documentación recopilada y aportada por las entidades públicas y privadas para establecer un informe final que contenga propuestas de actuación con criterios de eficiencia y eficacia (con posterior desarrollo en planes generales y especiales a nivel municipal).

* Propiciar la reflexión colectiva y compartida en torno al modelo territorial y a la acción de gobierno, implicando a la ciudadanía, los sectores privados y los poderes públicos locales en todo el proceso.

\subsection{METODOLOGÍA}

La metodología aplicada ha sido ad hoc, con un marcado carácter innovador, flexible, experimental y experiencial. En primer lugar se efectuó una recopilación y una síntesis analítica de los proyectos realizados desde los años 80 hasta ahora, estableciendo un catálogo documental (panel de experiencias) que pudiera ser útil en el diagnóstico previo. Destacan los Planes Estratégicos Locales y Provinciales, además del análisis de la documentación aportada por algunas personas que intervinieron en tres iniciativas de implantación de estructuras similares a los Consejos Económicos y Sociales de la ciudad desde I984. También se han tenido en cuenta el Plan Especial del Casco Histórico de Villena, el Plan Revita y el Plan Especial de la Huerta. A su vez se analizaron otros proyectos sectoriales, como el Proyecto de Integración del Ferrocarril y el estudio de la Estación del Ave de Villena, el Plan de Dinamización de Producto Turístico (PDPT), el programa de "participación ciudadana», el Pacto de Gobierno (20II-20I5) y el Plan Municipal de Igualdad.

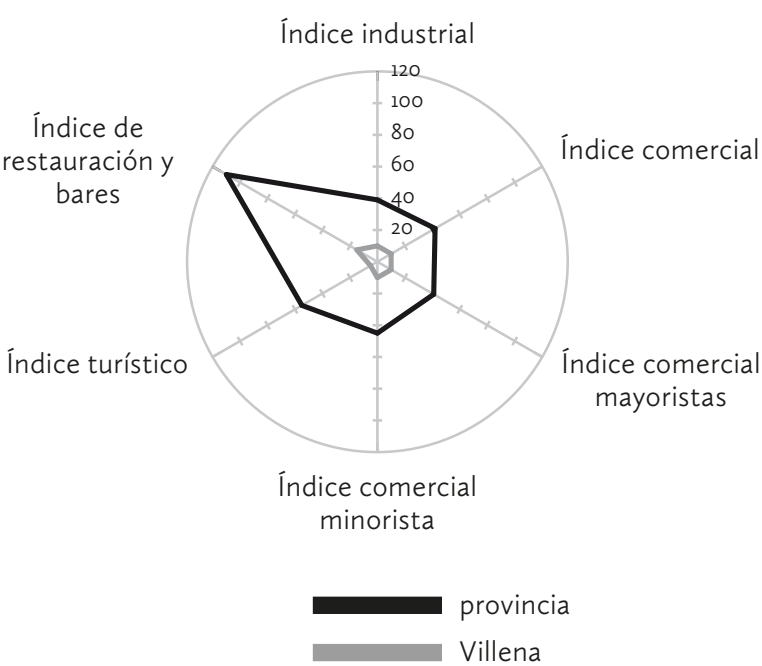

FIGURA 3. POLÍGONOS DE DESARROLLO VILLENA Y PROVINCIA DE ALICANTE Fuente: elaboración propia.

Para sistematizar la información obtenida se confeccionó una ficha de análisis con estos apartados: Motivación (Por qué), Objetivos (Para qué), Metodología (Cómo se hace), Contenidos (Qué es lo que se ha hecho hasta ahora), Resultados (Qué es lo que se ha conseguido), Conclusiones (Valoraciones). La intención fue tener una idea global del municipio, más allá de las meras cifras estadísticas y socioeconómicas que suelen utilizar habitualmente las consultoras foráneas en sus planificaciones estratégicas convencionales, en las que se detectó un desconocimiento de las circunstancias reales de los municipios objeto de evaluación.

En segundo lugar se aplicó un sistema de indicadores que midiera el índice industrial, comercial, industrial, las actividades comerciales, y que se comparó con 
otras poblaciones de la provincia de Alicante, en lo que se ha llamado el «polígono de desarrollo». De este modo, se identificaron y definieron las oportunidades de innovación territorial de Villena, en comparación con la totalidad de la provincia, para reforzar desde el punto de visto cuantitativo los aspectos cualitativos extraídos en los talleres participativos y las asambleas ciudadanas.

La ciudadanía también asumió de forma voluntaria un papel activo por medio de convocatorias abiertas y sectoriales a las que han acudido personas y colectivos de todo tipo. El motivo fue lograr un doble proceso: obtención de datos (talleres/ entrevistas/jornadas) y determinación de prioridades y necesidades (asambleas ciudadanas), generando al mismo tiempo una mayor implicación en el desarrollo de la ETV+i. En este sentido, no se planteó un diagnóstico ajeno a la población, sino implementar un instrumento que dotara al proyecto de continuidad a través de la constitución de un futuro Foro Económico y Social de Villena (FES). En febrero de 2013, coincidiendo con la $4 .^{\mathrm{a}}$ asamblea ciudadana celebrada en el Gabinete de Desarrollo Económico (La Tercia), un grupo de II vecinos y vecinas de Villena se postularon voluntariamente para preparar el borrador de reglamento del nuevo organismo ciudadano a lo largo de seis meses. La concepción participativa y participada (bottom up) de la ETV+i facilitó una visión transversal y global de la gestión municipal. Asimismo estableció relaciones con distintos sectores sociales (ciudadanos e institucionales) y aprovechó diversas herramientas metodológicas.

\begin{tabular}{|c|c|}
\hline UNIVERSO DE ESTUDIO & $\begin{array}{l}\text { Jóvenes, técnicos municipales, asociaciones } \\
\text { (sociosanitarias, festeras, culturales, vecinales, } \\
\text { etc.), tejido socioeconómico (empresas, sindicatos, } \\
\text { cooperativa, etc.) }\end{array}$ \\
\hline ÁMBITO GEOGRÁFICO & Villena \\
\hline ELEMENTO DE ANÁLISIS & Grupos de trabajo 4-5 personas \\
\hline TAMAÑO MUESTRAL & $\begin{array}{l}65 \text { grupos de trabajo } \\
315 \text { personas }\end{array}$ \\
\hline INFORMACIÓN RECOGIDA & $\begin{array}{l}\text { Opiniones sobre la función del municipio en la comarca, } \\
\text { elementos objeto de atención especial y acciones } \\
\text { necesarias para el municipio }\end{array}$ \\
\hline TRABAJO DE CAMPO & Mayo y octubre de 2012 \\
\hline
\end{tabular}

La intervención de la ciudadanía en el proceso de elaboración de la Estrategia Territorial de Villena+ Innovación se materializó en una serie de talleres participativos con una metodología ágil, innovadora, fácil de aplicar y adaptada a las necesidades del territorio.

a) Encuestas abiertas y cerradas. Esta técnica permitió producir y organizar con bastante rapidez un conjunto amplio de ideas sobre diversas temáticas (urbanismo, 
entidades sociales, economía, equipamientos, prospectiva de ciudad). La dinámica se dividió en tres partes. En un primer momento se distribuía a los participantes en grupos. A continuación debatían sobre el asunto expuesto. Por último, el moderador general exponía en un panel a todos los asistentes las conclusiones de cada grupo acerca de los aspectos positivos o negativos y las propuestas de cambio o nuevas propuestas.

b) Focus group. Sirvió para fomentar el dialogo en pequeños grupos sobre un tema específico. Generalmente esta dinámica se realizó con colectivos que a priori conocían de primera mano el tema que se iba a debatir, bien porque eran miembros de una asociación vinculada con el asunto o bien porque trabajaban en su día a día esas cuestiones. Ello fomentó una fuerte interacción entre todos los miembros, produciendo un efecto sinérgico que desencadenó un aluvión de respuestas y una lluvia de ideas entre todos los presentes.

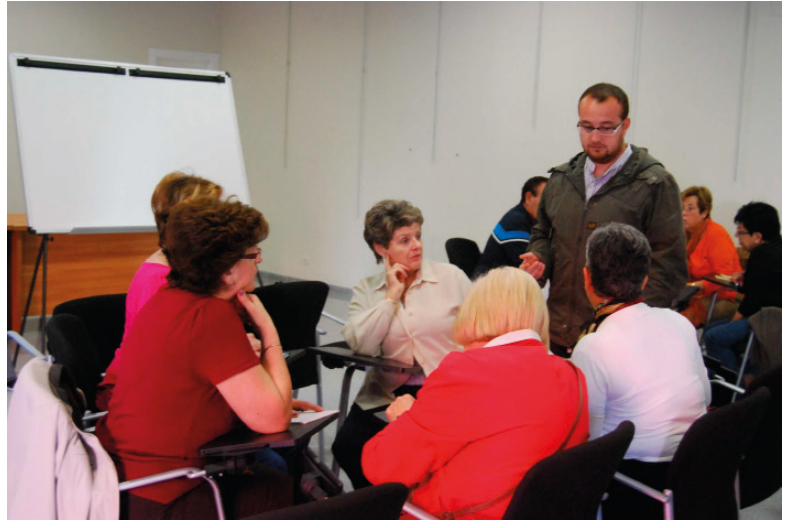

FIGURA 4. TALLERES PARTICIPATIVOS CON LA POBLACIÓN LOCAL

c) Elevator pitch. Se trata de plantear, en menos de un minuto, las principales ideas que se les ocurrían a los participantes en relación con la pregunta realizada. La dinámica del taller de participación siguió este patrón. En primer lugar cada participante exponía al resto de asistentes su visión del municipio, teniendo en cuenta el pasado, el presente y la idea de ciudad que querían para el futuro. Luego se dividían en tres grupos de cuatro participantes compuestos por representantes de un partido político o de un colectivo asociativo distinto. Cada grupo plasmaba de manera consensuada y en una ficha aquellos aspectos claves para el desarrollo social, territorial y económico de Villena. Finalmente el portavoz de cada grupo exponía al resto de asistentes las ideas reflejadas.

d) Mapas mentales y de percepción. Los mapas mentales son un método muy eficaz para extraer información de manera sintética. Se trató de aplicar un método lógico y creativo para expresar ideas que consistían, literalmente, en cartografiar las reflexiones sobre un tema. En este caso se utilizó en los talleres realizados con los jóvenes estudiantes de
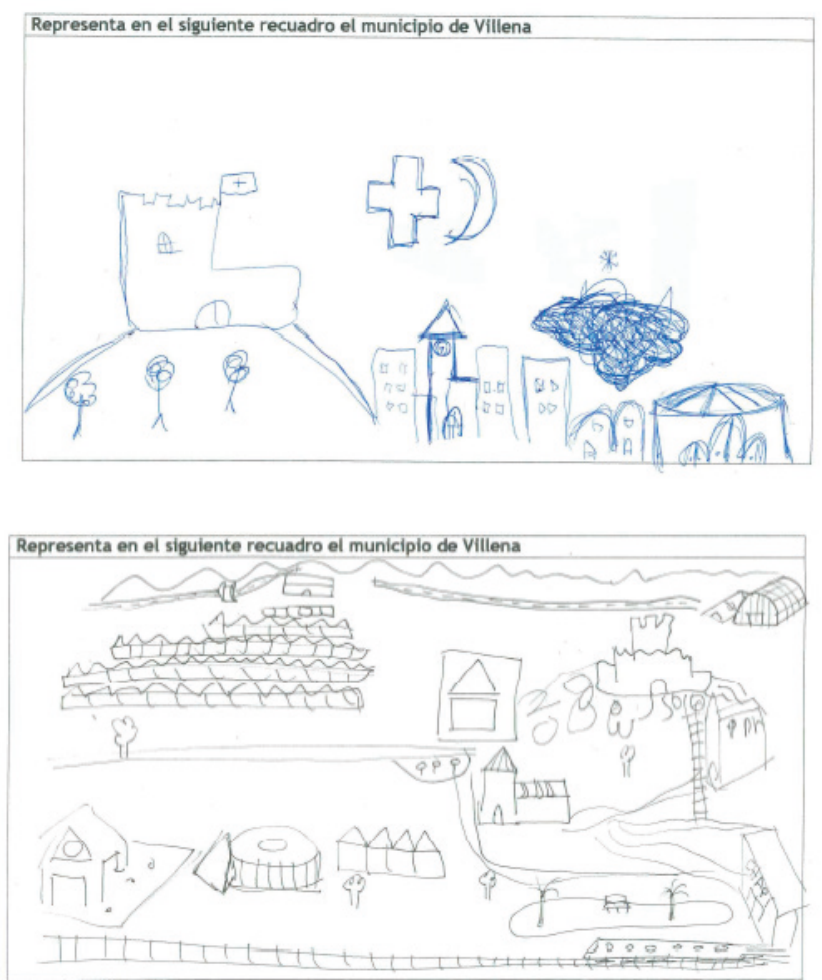

FIGURA 5. MAPAS MENTALES Y DE PERCEPCIÓN SOBRE LOS RECURSOS DEL MUNICIPIO DE VILLENA Fuente: elaboración propia. 
Bachillerato, que pudieron ilustrar su percepción de los principales elementos del municipio a través de símbolos, palabras e imágenes (FIG. 5). Hay que destacar los más de un centenar de mapas subjetivos o mentales, que se llevaron a cabo por parte de los alumnos/as de los tres institutos de bachillerato de la ciudad de Villena. En cuanto a los elementos e hitos monumentales, más destacados en sus dibujos resultó ser el castillo, en primer lugar con un 96,3\% de los resultados finales. Le sigue la plaza de toros, con un 8o,4\% y en tercer lugar el centro histórico y monumentos como Santiago, Santa María, barrios históricos, con un total de $64,5 \%$.

Por otra parte, se trató de un enfoque flexible ya que no es un método cerrado y fijo, sino que ha tenido la capacidad de adaptación para transformarse y dar respuesta a las novedades que iban surgiendo, incorporándolas de un modo sistemático. Así se ha contado con aquellos elementos que podrían ser útiles y enriquecedores.

FIGURA 6. FUNCIONES DE LA COMUNICACIÓN EN LA ETV+I

Fuente: elaboración propia

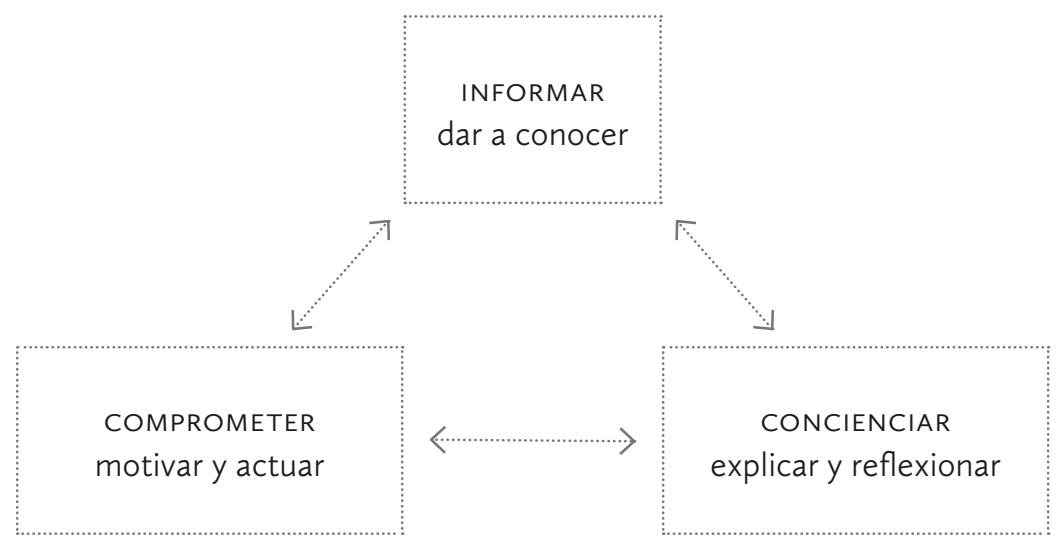

La comunicación cumplió cinco funciones esenciales: garantizar la transparencia de todo el proceso, informar y dar a conocer las acciones llevadas a cabo, concienciar a través de la explicación, incitar a la reflexión y, finalmente, lograr el compromiso de la población motivándola a participar en una iniciativa fundamental para consolidar la convivencia y la planificación futura del municipio. Entre 2012 y 2014, se han convocado siete ruedas de prensa y se han difundido 29 notas de prensa en los medios locales y comarcales (dos diarios en versión impresa y digital, dos emisoras de radio y una televisión comarcal), además de otros medios provinciales. Asimismo se ha creado un blog de la ETV+i en el que se han recogido todas las informaciones, actuando como cauce de interacción con los destinatarios. Y se han utilizado las redes sociales y el correo electrónico, con más de 350 direcciones, para convocar a la ciudadanía a cada taller y asamblea.

Así pues, la comunicación ha asumido diferentes funciones a lo largo de este proceso. Un medio y un fin: en tanto que instrumento de información para la sociedad, además de principio inspirador y rector en la gestión Un factor estratégico: con un desarrollo planificado y coherente para la consecución de unos objetivos. Una conversación: no solo se ha informado, sino que se ha habilitado la participación presencial y digital. Una redefinición: del «hacer para contar» o «contar lo que se hace», se ha pasado a «contar con los que hacen». Por eso no se ha buscado la «foto por la foto» con fines meramente propagandísticos Un escaparate: para 
darle visibilidad al trabajo colectivo de las personas que han participado en las distintas acciones (talleres, asambleas y reuniones), incrementando la transparencia y facilitando la accesibilidad.

En resumen, podemos afirmar que para poder participar, primero hay que conocer; para poder implicarse, es necesario comprender; y por último para poder compartir, se requiere confiar. Sólo así es posible conectar todas las voluntades personales en un proyecto común.

El sistema de la comunicación mediática convencional puede compararse a un iceberg, cuya parte visible, la cúspide, está ocupada por los medios (prensa, radio y televisión). Ellos se encargan habitualmente de darle visibilidad a aquellas cuestiones que configuran la «realidad» y «lo que pasa». Pero, además, tienen la potestad de fijar las agendas temáticas de los asuntos que se considerarían «relevantes» (agenda setting). Durante el desarrollo y ejecución de la ETv+i (y del Foro Económico y Social) los medios se han hecho eco, en todo momento, de las motivaciones, las acciones y los resultados mediante las sucesivas comparecencias públicas y, sobre todo, el envío constante de notas de prensa. Después, los periódicos, las radios y la televisión de ámbito local, comarcal y provincial se han encargado de (re)transmitir y hacer retornar (bidireccionalidad) esas informaciones al conjunto de la ciudadanía.

\section{CONTENIDO DE LA ETV+I}

La Estrategia Territorial de Villena + innovación (ETV+i) pretendió ser un instrumento flexible e inductivo y, por tanto, sometido a la dinámica social, económica, ambiental y cultural del municipio que permita una acción de gobierno programática y sistemática (planificada) a partir de un proceso previo de reflexión compartido y análisis participado. En este sentido la ETV+i se estructuró en áreas temáticas para el estudio y análisis propositivo, participativo y aplicado, apoyándonos en la transparencia y la comunicación (medios de comunicación, actividades formativas, reuniones sectoriales y blog). Entre los talleres realizados a todos los perfiles sociodemográficos y profesionales, comentados con anterioridad, destacó la idea del papel que el municipio podía ocupar en la comarca del Alto y Medio Vinalopó. En cuanto a los elementos a conservar y reforzar, los elegidos en primera opción fueron el centro histórico, los polígonos industriales, los espacios naturales y el turismo, como una actividad que se debía posicionarse mejor que lo está en la actualidad. Y entre las acciones necesarias, en primera instancia destacaron las de tipo instrumental vinculadas a la ordenación del territorio (como los Planes Generales de Ordenación Urbana y las de preservación y gestión de los recursos naturales) y las de tipo socioeconómico, como las del fomento de nuevos yacimientos de empleo, apoyo al emprendedor y reactivación del empleo (FIG. 7).

No obstante, del contenido de los talleres podríamos destacar los siguientes resultados generales:

a) La necesidad de que haya continuidad en la gestión del gobierno municipal, ya que la alternancia de las últimas cuatro legislaturas, un gobierno diferente 
FIGURA 7. FUNCIÓN QUE PUEDE CUMPLIR EL MUNICIPIO DE VILLENA EN EL CONTEXTO DE LAS COMARCAS DEL VINALOPÓ (ALICANTE)

Fuente: elaboración propia.

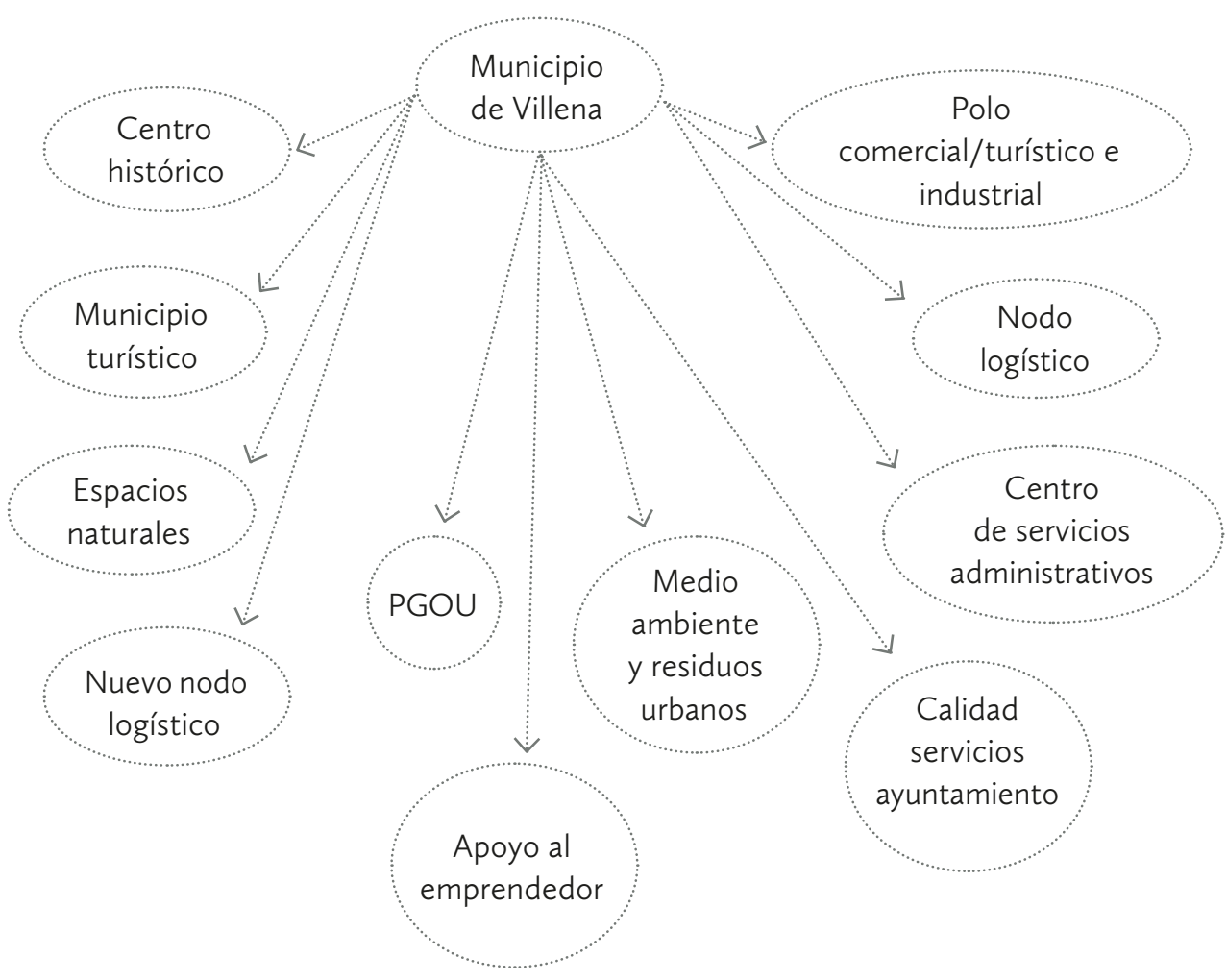

cada cuatro años, no ha podido consolidar una línea de trabajo en los proyectos previstos. A ello hay que añadir la falta de liderazgo político.

b) La apuesta por una diversificación de las actividades económicas (agricultura, turismo, patrimonio, comercio, nodo empresarial, etc.).

c) La aplicación y generación de instrumentos y herramientas de gestión municipal (PGOU, coordinación de iniciativas de los servicios municipales, Plan Integral de la Huerta, etc.).

d) Revalorización del entorno y gestión de los recursos territoriales (optimización de los recursos municipales, abastecimiento y racionalización de la explotación de los acuíferos, residuos y basuras, etc.) que doten de coherencia la gestión de los recursos locales y del territorio.

e) Que se tenga más en cuenta a los ciudadanos, a través de la participación y de una mayor implicación de la ciudadanía. No solo cuando llegan elecciones.

\section{LA CONSTITUCIÓN DE UN CONSEJO ECONÓMICO Y SOCIAL EN VILLENA, DESDE LA PARTICIPACIÓN CIUDADANA}

En la $4 \cdot{ }^{\mathrm{a}}$ asamblea ciudadana celebrada en el marco de la ETV+i, (febrero de 2013), se estableció crear un Consejo Económico y Social como órgano autónomo, consultivo, propositivo y representativo de todos los ciudadanos/as de Villena. Para ello se eligió al grupo gestor del futuro Foro Económico y Social (FES). En las anteriores reuniones de trabajo, realizadas desde julio de 2012 hasta febrero de 20I3, se había 
evidenciado la necesidad de este órgano municipal. Las diferentes convocatorias abiertas, no solo representativas, se realizaron a través de mailing, acudiendo una media de 65 vecinos y vecinas en cada una de ellas. En estas fases preliminares a la asamblea de febrero se detectó la conveniencia de cambiar las cosas, poniéndose de manifiesto el sentimiento ciudadano de que ninguno sobraba en este proceso. Así, bajo la tutela y acompañamiento del profesor Vicente Zapata, de la Universidad de la Laguna, se empezaron a definir los atributos del futuro Consejo Económico y Social del municipio, los pasos a seguir en este proceso ciudadano, su utilidad y finalidad. Algunos términos que resumen las propuestas presentadas fueron: voluntario, transparente, abierto, actitud positiva, acuerdos, coherencia, conciliación, confianza, constancia, diálogo, esperanza, generosidad, utilidad, voluntad, integración.

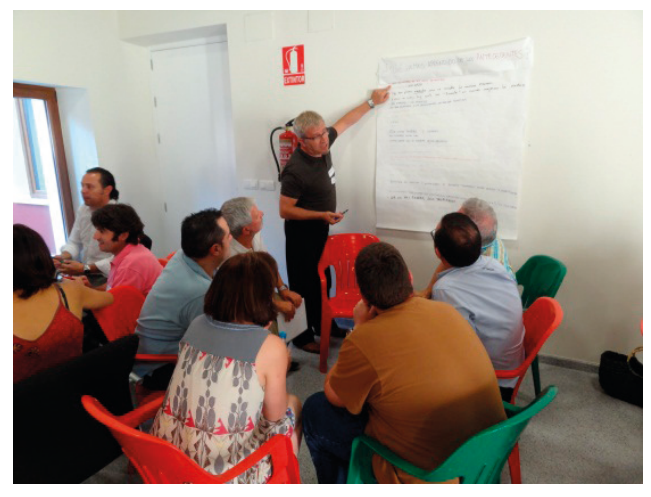

En una de las sesiones, distribuidos por grupos, la ciudadanía debatió, reflexionó, propuso y respondió a seis preguntas, compartiendo las conclusiones con el resto de asistentes a través de sus portavoces. A la primera pregunta de ¿a qué necesidad responde una estructura orgánica ciudadana?, la contestación fue que respondía a una cierta insatisfacción general que animaba a cambiar las formas de participar en el proceso de desarrollo municipal mediante el impulso de estrategias colaborativas e integradoras. En la segunda, ¿qué ventajas reportará?, se afirmó que reportaría un cauce de diálogo y acción conjunta que permitirá construir un municipio que responda a un modelo compartido. La tercera, ¿qué dificultades

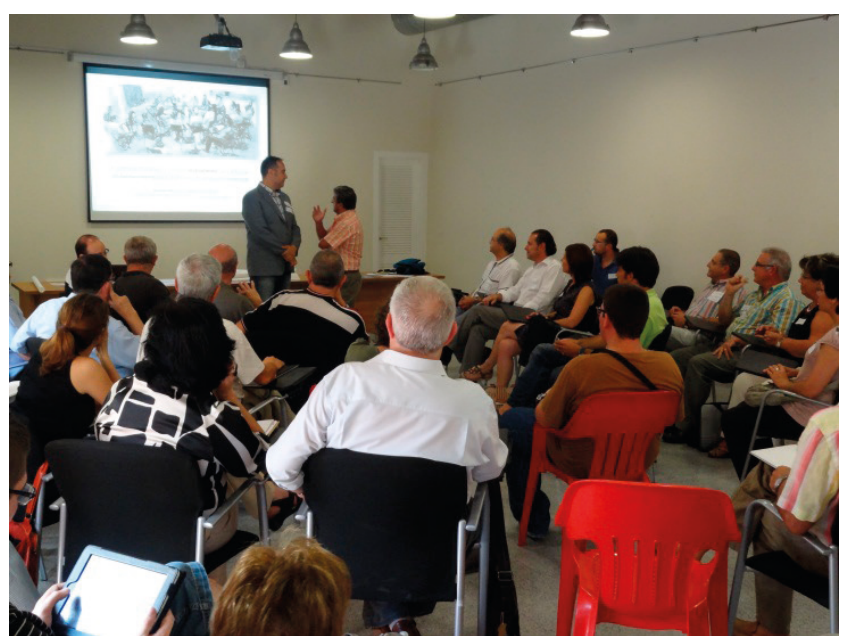

FIGURAS 8 Y 9. ASAMBLEAS CIUDADANAS DESDE JULIO DE 2012 HASTA FEBRERO DE 2013 Fuente: elaboración propia. encontraremos?, se aludió a que habría que salvar la desconfianza, superar los intereses particulares y gestionar la frustración e impaciencia que provocan las experiencias previas.

La cuarta, ¿qué hemos aprendido de los antecedentes?, arrojó la idea de que se dispone de capital humano e iniciativa para construir nuevos procesos en los que el liderazgo compartido y la constancia aseguren la continuidad que son imprescindibles y necesarias. La quinta, ¿quién/qué entidad no debe faltar?, obtuvo la respuesta de que debe participar toda aquella persona y colectivo que desee aportar su punto de vista y su colaboración para mejorar de forma constructiva la realidad municipal, haciendo sostenible el proceso. Y a la última, ¿cómo iniciamos el proceso?, se contestó que dialogando y consensuando objetivos, procedimiento y calendario de trabajo que haga avanzar un proceso ya iniciado en el que deben seguir integrándose actores todavía ausentes. 


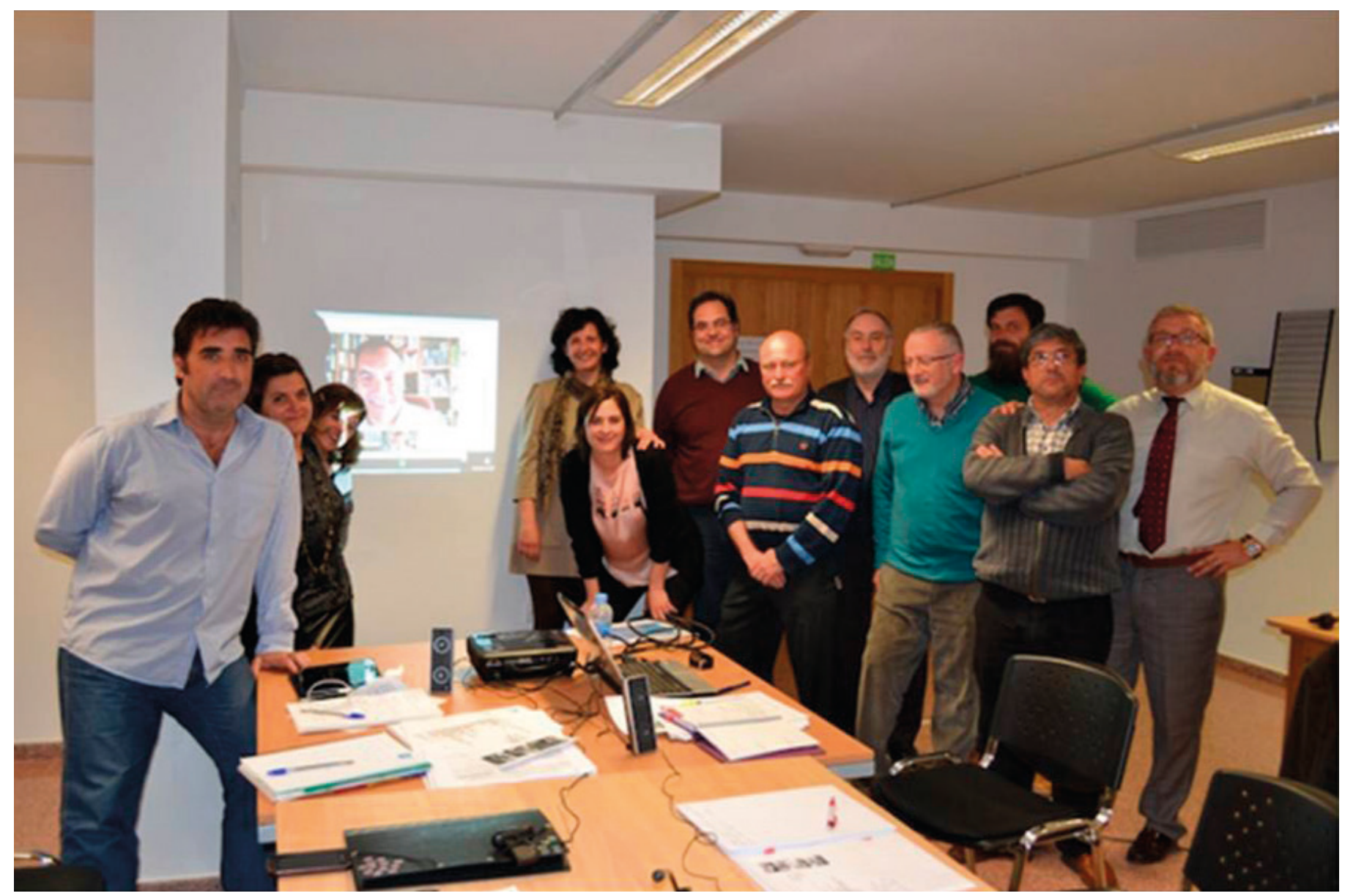

FIGURA 1O. GRUPO GESTOR DEL CONSEJO ECONÓMICO Y SOCIAL DE VILLENA EN UNA REUNIÓN DE TRABAJO EN LA SEDE UNIVERSITARIA. AL FONDO VICENTE ZAPATA POR VIDEOCONFERENCIA

Fuente: elaboración propia

En la asamblea de febrero de 2013, como ya hemos señalado anteriormente, se constituyó un grupo de trabajo para redactar una propuesta de reglamento, que sería debatida y consensuada en las asambleas de octubre y diciembre de 2013 y en la última celebrada en abril de 20I4. Ya en esta última se recogieron los contenidos, funciones, componentes y directrices generales del Foro Económico y Social de Villena. Desde febrero de 2013 hasta el mes de abril de 20I4, este grupo de ciudadanos trabajó de forma voluntaria y muy eficazmente por su municipio. Fueron II ciudadanos y ciudadanas procedentes de sectores socioeconómicos dispares (jubilados, empresarios, autónomos, parados, funcionarios, trabajadores por cuenta ajena), de ideologías diferentes, de segmentos de edad muy diversos, pero con la misma motivación de contribuir a mejorar su ciudad (FIG. IO).

El «mandato» de la Asamblea el I3 de febrero de 2013, al Grupo de Trabajo fue elaborar un documento de base para la creación de una estructura del tipo Consejo Social de la Ciudad. Asimismo se enunciaban una serie de premisas para garantizar la sostenibilidad y la calidad del proceso participativo que concluirá con 
la formulación de las directrices general de la estructura participativa de carácter municipal. Éstas tienen que ver con la actuación del propio Grupo de Trabajo que adquirió notable protagonismo a partir de entonces en relación con el impulso de las acciones conducentes a lograr el objetivo de dotar a Villena de un Foro Económico y Social, mediante una dinámica de trabajo que adquirió una dimensión cada vez más original por su desarrollo de abajo hacia arriba, situando a la ciudadanía en el centro del proceso.

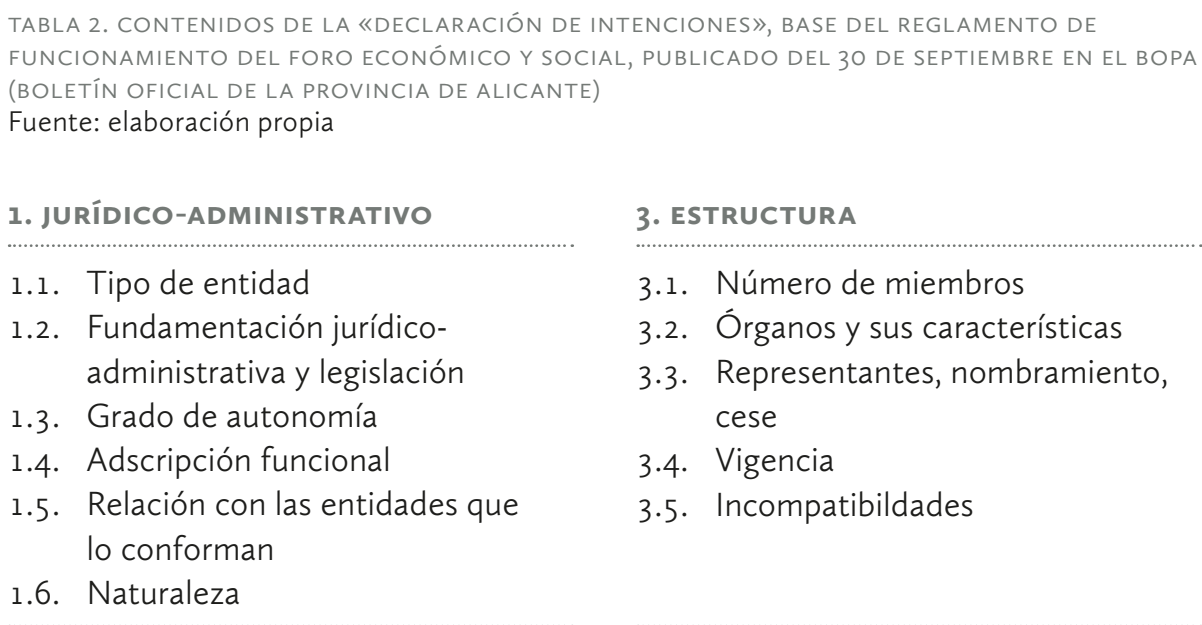

\section{PRINCIPIOS BÁSICOS}

2.1. Configuración

2.2. Carácter

2.3. Fines

2.4. Objetivos

2.5. Finalidades

2.6. Funciones

\section{FUNCIONAMIENTO}

4.1. Dinámica de funcionamiento

4.2. Régimen de sesiones

4.2.1. Convocatorias

4.2.2. Quorum

4.2.3. Adopción de acuerdos

4.2.4. Actas

4.3. Actividades propias: memorias, informes, estudios, etc.

4.4. Recursos y medios para su funcionamiento

4.5. Régimen económico

4.6. Imagen corporativa

4.7. Denominación

Con el objetivo de centrar adecuadamente las tareas conducentes a la formulación de las bases de la estructura participativa, se definió un esquema de temas o aspectos fundamentales que debían ser abordados y resueltos adaptándose a las particularidades de Villena. Por ello, y de cara la redacción del documento que sirviera de base para la elaboración del reglamento del Foro Económico y Social, se organizó el documento en torno a cuatro grandes bloques: jurídico-administrativo, principios básicos, estructura y funcionamiento (TABLA 2). Así se configuró lo 
que se vino a denominar Documento de Intenciones por parte del Grupo de Trabajo, elaborándose diversas versiones del mismo hasta su presentación definitiva a la Asamblea, para ser ratificado por la misma después, en abril de 20I4, y antes de su publicación definitiva en el вора (Boletín de la Provincia de Alicante), el 30 de septiembre de 2014.

Durante todas las sesiones del grupo de trabajo (más de 30 reuniones de dos horas de duración cada una de ellas), llevadas a cabo de marzo de 2013 a abril de 20I4, se levantaron actas de los acuerdos tomados con el fin de sistematizar y evaluar los avances. En los meses de julio y agosto de 2013, se mantuvieron encuentros con todos los partidos políticos y sindicatos villenenses, así como con asociaciones juveniles y empresariales. Se quiso hacer partícipes a estos colectivos del proceso y de la importancia de que las bases que sustentan el Foro Económico y Social de Villena fueran lo más participadas posible, buscando el máximo consenso. De algún modo, se ha favorecido un aprendizaje colectivo, una experiencia compartida y un diálogo social entre todos los ciudadanos que voluntariamente han decidido implicarse y comprometerse. No se trata de una participación por decreto o por cupo («representatividad legitimada»), sino de un proceso abierto, flexible, original y transparente para que la ciudadanía se implique desde el principio en este proceso comunal a medio y largo plazo.

El papel de los políticos locales, sobre todo el de los que conforman la coalición de gobierno en el ayuntamiento de Villena, también fue destacado por su

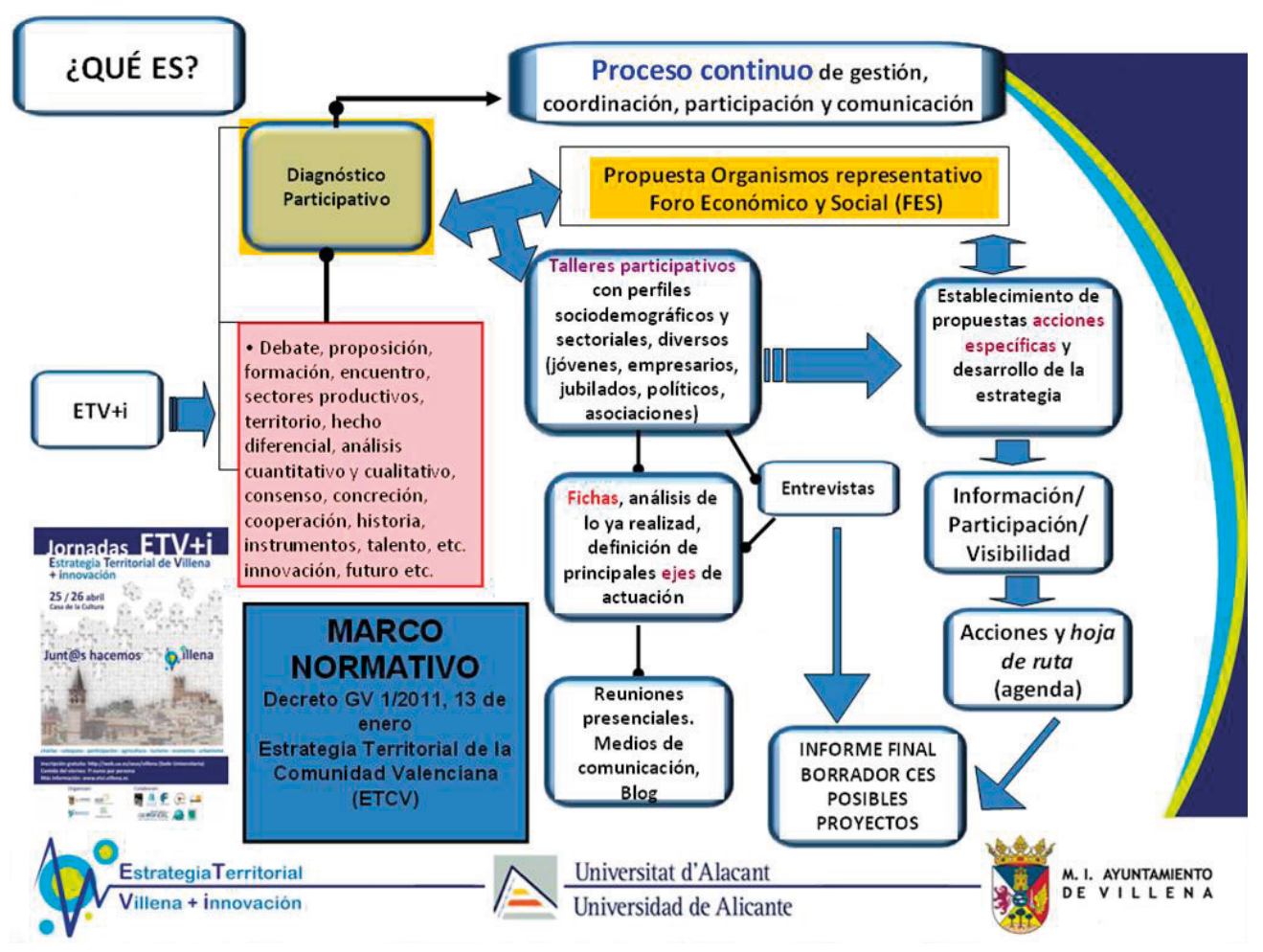

FIGURA 11. ESQUEMA SOBRE LAS FASES Y TRABAJO DE LA ETV+I (2012-2013)

Fuente: elaboración propia 
voluntad «de dejar hacer». No han interferido en ningún momento y han acompañado y participado el proceso como unos ciudadanos más en todo momento. Así se ha intentado no desnaturalizar e influir en la metodología de actuación. Además, ha sido fundamental la tutorización y el acompañamiento que ha desempeñado la Universidad de Alicante, materializados en la Sede de Villena. El departamento de Geografía Humana se ha encargado de realizar ese diagnóstico participativo, ha articulado el equipo de trabajo y ha posibilitado una metodo-

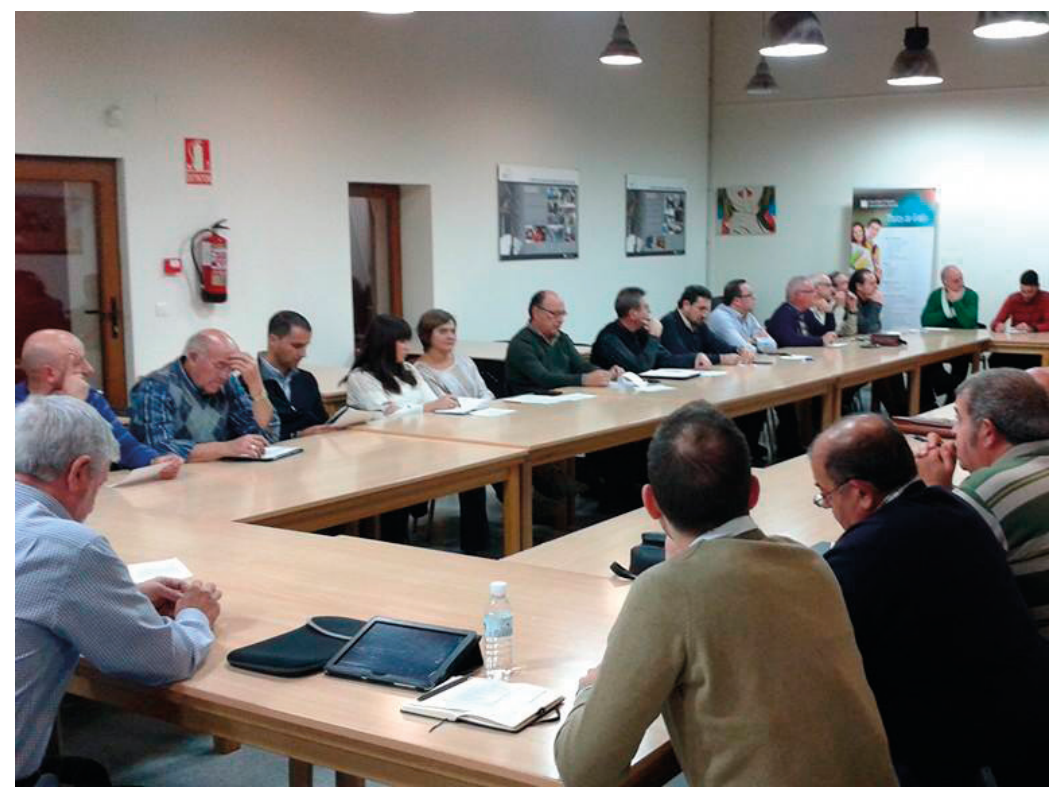

FIGURA 12. MIEMBROS DEL FORO ECONÓMICO Y SOCIAL (FES) EN SU CONSTITUCIÓN EN NOVIEMBRE DE 2014 logía flexible y propia. Para reforzar las acciones de comunicación, formación y la metodología participativa, se desarrollaron a finales del mes de abril de 20I3, unas jornadas sobre la ETv+i con el título de Junt@s hacemos Villena. En ellas se contó con la presencia de un panel de expertos nacionales (de la Universidad de Alicante y otras instituciones académicas superiores, junto con profesionales de otras instituciones), que trataron aspectos vinculados al diagnóstico: diversificación económica, fomento del talento, turismo, actividades productivas vinculadas a los aprovechamientos agrarios, infraestructuras y equipamientos, marca ciudad, etc. Por otra parte, también se establecieron talleres con el público asistente y los componentes del grupo gestor del FES, presentándose algunos de los avances del diagnóstico establecido en la ETV+i. El ix Coloquio Nacional de Desarrollo Local organizado por el grupo de trabajo de la Asociación de Geógrafos Españoles (AGE) durante el mes de junio de 2013, llevó a cabo en Villena su 2. ${ }^{a}$ ponencia con el título Los procesos de innovación social mediante la participación ciudadana como estrategia para el desarrollo local, a cargo del profesor Vicente Zapata. En la sesión participaron también los miembros del grupo de trabajo promotor del FEs, ante más de un centenar de asistentes venidos de universidades españolas y extranjeras (Reino Unido, Italia, Colombia, México) ${ }^{9}$.

Durante los últimos meses de 20I4, el Foro Económico y Social de Villena (FEs) terminó de elegir a sus últimos integrantes, definiendo el procedimiento de actuación, las estrategias de visibilidad y comunicación, así como realizar una prelación sobre los principales problemas que afectan al municipio y necesarios de

9. http://web.ua.es/es/seus/villena/cursos-y-jornadas/2012-2013/ix-coloquio-desarrollo-local/ix-coloquio-nacional-de-desarrollo-local.html 
ser abordados. Al final se ha constituido este nuevo órgano ciudadano que servirá para deliberar, adoptar decisiones y proponer medidas sobre asuntos de interés común que afecten a la ciudadanía y a la gestión del municipio. Está integrado por 38 miembros, más un representante de cada grupo, coalición o partido político que haya obtenido representación en el Ayuntamiento en las elecciones municipales.

Así, sus representantes fueron refrendados por el Pleno del Ayuntamiento en el mes de octubre de 20I4. La distribución según sus perfiles sociodemográficos y sectores de actividad fue la siguiente: jóvenes (I), mujeres (I), mayores (I), inmigrantes (I), asociaciones sociales y sanitarias (5), vecinales y de consumidores (5), culturales, deportivas y educativas (5), medio ambientales (I), organizaciones empresariales (3) y profesionales (3), además de sindicatos (3) y partidos políticos (4). La Universidad de Alicante (2), institución académica con presencia en nuestra ciudad a través de su Sede Universitaria, también forma parte del FES.

\section{RESULTADOS Y CONCLUSIONES}

La ETV+i de Villena, trató de favorecer un proceso genuino y diferente en la Comunidad Valenciana, que no sólo se quedara en un proyecto de diagnóstico, sino que facilitara un procedimiento que definiera líneas estratégicas y acciones específicas, dando lugar a un proceso a medio y largo plazo. Todo ello acompañado y reforzado por el trabajo que comenzó el grupo promotor del Foro Económico y Social de Villena (FORO) y que se ha constituido como un organismo consultivo y ciudadano, ratificado y conformado en noviembre de 20I4. Todo ello acompañado por el trabajo voluntario de un grupo de ciudadanos que trabajó en la propuesta del reglamento y sentó las bases de esta estructura orgánica (FORO) a la medida y necesidades de Villena. Con el apoyo de la Universidad de Alicante, que lo ha tutelado, acompañado y reforzado con otras acciones, y con la complicidad de los políticos que han generado las condiciones necesarias, para no «manipular» el proceso. Se realizó un informe final, no sólo de diagnóstico, sino también propositivo, que contó con la participación de abajo a arriba de la ciudadanía. De esta forma se aplicó la metodología investigación-acción, y que encajan con las nuevas directrices exigidas en los Fondos de Cohesión Europea (2014-2020). Así el documentos denominado Estrategia Territorial, contiene diversos capítulos con la Introducción (contextualización conceptual de la iniciativa en el marco normativo de la ETCV, el desarrollo local y la innovación territorial); Memoria (explicación de los objetivos, metodología e instrumentos de la ETV+i y descripción del desarrollo, ejecución y cronograma de las acciones llevadas a cabo); Resultados (diagnóstico con las valoraciones cuantitativas y cualitativas organizadas por áreas temáticas de gestión municipal); Conclusiones (reflexiones finales y propuestas/líneas de actuación futuras); Anexos (documentos, gráficos, material audiovisual y fotográfico, encuestas, entrevistas, datos sobre el equipo redactor, hemeroteca (notas de prensa), etc.

En definitiva, todo ello ha contribuido a un aprendizaje colectivo y compartido, desde el compromiso de la ciudadanía, el diálogo social y la implicación de las instituciones. 


\section{REFERENCIAS BIBLIOGRÁFICAS}

Delfour, C. (2007): España, las autonomías y Europa. Ensayo sobre la invención de nuevos modos de organización territorial y de gobernanza, editorial TREA, Gijón.

Font, J., Montero, J.R. \& Torcal, M. (2006) (eds.): Ciudadanos, asociaciones y participación en España, Centro de Investigaciones Sociológicas (CıS), Madrid.

Heras Hernández, F. (2002): Entre Tantos. Guía práctica para dinamizar procesos participativos sobre problemas ambientales y sostenibilidad, GEA, Valladolid.

Martínez Puche, A. (20io): El desarrollo local en un contexto globalizado. Cohesión territorial, gobernanza, políticas públicas e instrumentos de innovación. Estudio de casos en el Corredor Industrial del Vinalopó (Alicante), (Tesis doctoral s.p.), Universidad de Alicante.

- (2012): «Análisis de las redes empresariales y su incidencia territorial. Transferencia tecnológica, aprendizaje e innovación», Revista de Estudios Andaluces 29, Sevilla, pp. I7-57.

Martínez Puche, A. \& Calvo Palomares, R. (coords.) (20I2): Valoraciones técnicas y repercusiones territoriales sobre el ejercicio profesional del desarrollo local. Presente y futuro, GEOBINDEL-UA, ed. Germania, Alzira.

Martínez Puche, A., Martínez Puche, S., Palací, Zapata, V.M. \& Expósito, M. (20i3): «La estrategia territorial de Villena+innovación (ETV+i). Un proceso experimental y aplicado de participación ciudana», en CAlvo, R. et alii (coords.), Ciudadanía empoderada: cultura y participación para el desarrollo local, ed. Germania, Alzira.

Martínez Puche, A., Pérez, D. \& Sancho Carbonell, I. (2000): Eines per al desenvolupament local/Herramientas para el desarrollo local, CEDER-Aitana y Universidad de Alicante, Cocentaina.

Montero, J.R., Font, J. \& Trocal, M. (2006): Ciudadanos, asociaciones y participación en España, Centro de Investigaciones Sociológicas (CIS), Madrid.

Natera Peral, A. (2005): «La gobernanza como modo emergente de gobierno y gestión pública» GAPP 33-34, INAP, Madrid, pp. 53-65.

PuIG, A. (2009): Marca ciudad. Cómo rediseñarla para asegurar un futuro espléndido para todos, ed. Paidós, Barcelona.

Romero GonzÁLEZ, J. (2005): «El gobierno del territorio en España. Balance de iniciativas de coordinación y cooperación territorial» Boletín de la A.G.E. 39, Madrid, pp. 59-86.

Romero, J. \& FARINós, J. (2OII): «Redescubriendo la gobernanza más allá del buen gobierno. Democracia como base, desarrollo territorial como resultado», Boletín de la Asociación de Geógrafos Españoles (AGE) 56, pp. 295-319.

Sanchís Palacio, J.R. (2006): El papel del agente de empleo y desarrollo local en la implementación de las políticas locales de empleo y en la creación de empresas en España. Estudio empírico y análisis comparativo entre CC.AA., Ministerio de Trabajo y Asuntos Sociales, Madrid.

VAlCÁRCEL-Resalt, G. (I996): «El enfoque local del desarrollo rural. De la teoría a la práctica», en Valcárcel, G. Troitiño, M.A. \& Esteban, L., Desarrollo local y medio ambiente: La Iniciativa Comunitaria LEADER, Diputación de Cuenca, Cuenca, pp. 29-6I.

Vázquez Barquero, A. (I993): Política económica local, editorial Pirámide, Madrid.

Vintró Castells, J. \& Bilbao Ubillos, J.M. (20II): Participación ciudadana y prodecimiento legislativo: de la experiencia española a la iniciativa ciudadana europea, Centro de Estudios Políticos y Constitucionales, Madrid.

ZAPATA HeRnÁNDEZ, V.M (dir.) (2008): Guía práctica para El trabajo técnico en desarrollo rural, Extensión Universitaria, Universitat Jaume ı, Castellón. 


\section{Artículos · Articles}

19 María del Pilar Borderías URIBEondo

Reflexiones al finalizar la «Década de las Naciones Unidas de Educación para el Desarrollo Sostenible 2005-2014»: referencias ambientales en los Grados de la UNED y aportación de la Geografía a la EDS / Reflections at the end of the 'United Nations Decade of Education for Sustainable Development 2005-2014': environmental references in the Degree of UNED and contribution of Geography to ESD

\section{Jesús Calzadilla, José Luis López \& Aurelio VilLa}

Análisis espacial del desarrollo económico rural a nivel territorial / Spatial analysis at territorial level of rural economic development

47 David Cocero Matesanz, José Miguel Santos Preciado, María del Carmen Muguruza Cañas, fernando Santa Cecilia Mateos, maría Victoria Azcárate luxán, María del Pilar Borderías Uribeondo \& María Eugenia Prieto Flores

La utilización en los estudios urbanos de la cartografía catastral y su manejo mediante un SIG: aplicación al municipio de Getafe (Madrid) / The use in urban studies of cadastral mapping and management through GIS: application to the town of Getafe (Madrid)

73 Juan Antonio Fernández-Cañadas López-Peláez, María Palomo Segovia \& LUis Pantoja Trigueros

Delimitación espacial de las zonas probables de salida de aludes en el macizo de Peñalara mediante el uso de SIG / Spatial delimitation of the possible output zones of avalanches in the Peñalara massif using GIS techniques

Jesús Miguel García Rodríguez

Importancia patrimonial y territorial del legado hidroeléctrico en el curso bajo del Río Saja (Cantabria) / Patrimonial and territorial importance of hydroelectric legacy in the lower reaches of Saja (Cantabria)

\section{Beatriz Martínez de Teresa}

Paisaje urbano y problemática medioambiental: el caso del distrito de Retiro (Madrid) / Cityscape and environmental issues: the case of Retiro district (Madrid)

antonio Martínez Puche, Salvador Martínez Puche, joaquín Palací Soler \& Vicente Zapata Hernández

Estrategias territoriales participativas como instrumentos de diagnóstico y prospectiva, en el contexto europeo de los fondos de cohesión 2014-2020: el caso de Villena (Alicante) / Territorial participatory strategies as instruments of diagnosis and prospective, in the European context of the funds of cohesion 2014-2020 in Villena (Alicante)
185 Francisco José Morales Yago

Evolución de la jerarquía urbana en la Región de Murcia tras más de treinta años de la aprobación del estatuto de autonomía (1982-2014) / Evolution of urban hierarchy in the Region of Murcia thirty years after the adoption of the statute of autonomy (1982-2014)

205 José Luis Rodríguez García

Conservación y gestión del paisaje en el Campo de Albacete / Landscape conservation and management in the Campo de Albacete

227 XANTI SUdUPE Zabalo

El abandono en el paisaje de periferia y periurbano de Bilbao / Abandonment in the periphery and peri-urban landscape of Bilbao

257 M. Antonio Zárate Martín \& InÉs Ortíz Álvarez

Estrategias para la conservación y gestión sostenible de los paisajes culturales urbanos en México y España / Strategies for the conservation and sustainable management of the urban cultural landscapes in México and Spain

\section{MARÍA DEL CARMEN ZORRILLA LASSUS}

La puesta en valor del paisaje a través de la educación, propuesta para el desarrollo de la Isla de Vieques (Puerto Rico) / The enhancement of landscape through education proposal for the development of the island of Vieques (Puerto Rico)

\section{Recensión de un libro · Book Review}

315 Borderías Uribeondo, M.P. \& Muguruza Cañas, M.C.: Impacto ambiental 6101301GRoiAol. (María José Aguilera ArilLa)

\section{Imágenes y palabras · Pictures and words}

323 Francisco josé Morales Yago

Portmán (La Unión-Cartagena): ¿Crónica de un impacto medioambiental en vías de solución? / Portmán (La Unión-Cartagena): chronicle of an environmental impact way of solution?

\section{Comentario de material didáctico · Comment of didactic material}

Mendoza Vargas, Héctor (coord.): Estudios de geografía humana de México. (Alejandro García Ferrero)

Historia de la Geografía Española • History of Geography in Spain 335 Nota preliminar

337 Aurelio Nieto Codina

Paisaje y Geografía en la obra de Eduardo Hernández-Pacheco / Landscape and Geography in the work of Eduardo Hernández-Pacheco 